\title{
Intervensi pada perilaku bidan tentang pelaksanaan inisiasi menyusu dini dengan menggunakan layanan pesan singkat
}

\author{
Intervention on midwife behavior about early initiation of \\ breastfeeding practice using short message service
}

Widya Lionita ${ }^{1}$, Trisasi Lestari ${ }^{2}$, Ova Emilia $^{3}$

Dikirim: 14 Juni 2016

Diterbitkan: 1 Februari 2017

\begin{abstract}
Purpose: This research examined the effects of an intervention by delivering short message service towards midwife behavior. Methods: This research was a quasi-experimental study with pre and post test design using control group. A total of 64 midwives in Palembang participated until data extraction. About 18 themes of short messages were delivered through participants' mobile phone. Data were analyzed by univariate, bivariate, and linear regression tests. Results: Results showed that the intervention improved early breastfeeding perceptions by about $7.3 \% \quad(p=0.0308)$. Participants' knowledge was increased after intervention although there was no significant mean difference between groups. Almost all participants (over 80\%) practiced imperfect early breastfeeding, especially in giving information since antenatal care, short-duration, and directing baby for sucking mother's nipple. Conclusion: Not all of participants facilitated early breastfeeding in every birth because of other factors such as unsupported mother and infant's condition. Early initiation of breastfeeding is not easily implemented by health staff. It is better that midwives could motivate mothers to breastfeed within 1 hour since antenatal care. The important keys are having high commitment and confidence which contribute to midwives' belief for practicing every step in every birth. We concluded that this research should be continued for long-term-analysis to give more significant results.
\end{abstract}

Keywords: early initiation of breastfeeding; intervention; short message; behavior; midwives

\footnotetext{
${ }^{1}$ Departemen Perilaku Kesehatan, Lingkungan dan Kedokteran Sosial, Fakultas Kedokteran, Universitas Gadjah Mada (Email: widylionita@gmail.com)

${ }^{2}$ Departemen Kebijakan dan Manajemen Kesehatan, Fakultas Kedokteran, Universitas Gadjah Mada

${ }^{3}$ Fakultas Kedokteran, Universitas Gadjah Mada
} 


\section{PENDAHULUAN}

Sekitar 3 juta kematian bayi terjadi dalam periode 1 bulan pertama, bahkan sebagian dari jumlah kematian tersebut terjadi pada 24 jam setelah persalinan (1). Risiko kematian bayi meningkat 33 kali lebih tinggi di negara-negara berkembang (2). Laporan SDKI tahun 2012 menunjukkan indikator kematian bayi dan ibu di Indonesia menunjukkan angka yang memprihatinkan. Peningkatan justru terjadi pada Angka Kematian Ibu (AKI) menjadi 359 per 100.000 kelahiran hidup, sedangkan Angka Kematian Bayi (AKB) tetap dengan 32 per 1000 kelahiran hidup. Menurut Mochtar, tiga penyebab utama dari kematian bayi baru lahir seperti kelahiran prematur, komplikasi selama kehamilan, dan infeksi neonatal, sedangkan kematian ibu di negara berkembang sebagian besar disebabkan perdarahan, penyakit infeksi dan eklamsi (3).

Kota Palembang menyumbang kematian bayi sebanyak 168 kasus pada tahun 2013 (6 per 100 kelahiran hidup) yang didominasi kematian neonatus. Angka tersebut meningkat 2 kali lipat dibandingkan dengan tahun sebelumnya, sedangkan AKI sebesar 43 per 100.000 kelahiran hidup pada tahun yang sama (4).

Sebagai upaya untuk menekan AKI dan AKB di Indonesia, pemerintah mengeluarkan regulasi terbaru, yakni PP No. 33 Tahun 2012 tentang Pemberian ASI eksklusif. Manfaat pemberian ASI sejak 0-6 bulan pertama banyak memberikan perlindungan terhadap kejadian penyakit infeksi dan meningkatkan kekebalan tubuh bayi, kecerdasan dan aktivitas bersifat akademik pada periode 6,5 tahun pertama (5).

World health organization (WHO) menyatakan peningkatan cakupan dan durasi pemberian ASI yang lebih lama dipengaruhi oleh inisiasi menyusu dalam 1 jam setelah proses persalinan atau Inisiasi Menyusui Dini (IMD) dan diberikan secara eksklusif (6). Namun, praktik IMD belum dilakukan semua tenaga penolong persalinan. Afifah menyatakan faktor penghambat IMD adalah tenaga penolong persalinan yang tidak paham dan tidak berani melakukan IMD (7). Salah satu faktor penentu kinerja bidan dalam melaksanakan IMD adalah pengetahuan dan persepsi bidan (8).

Pembangunan teknologi memberikan peluang untuk meningkatkan derajat dan layanan kesehatan melalui mobile health (mHealth). Ponsel menjadi sarana intervensi terkenal karena biaya murah, digunakan semua orang, dan merekam, menyimpan, mengatur dan menyebarkan informasi pada waktu bersamaan (9). Aplikasi mHealth di Indonesia telah dimanfaatkan pada sistem informasi dan pengelolaan kesehatan ibu dan anak (10). Akan tetapi belum ditemukan adanya bukti pemanfaatan yang ditujukan kepada tenaga penolong persalinan untuk meningkatkan capaian IMD. Oleh karena itu, penelitian ini dilaksanakan dengan tujuan untuk mengetahui pengaruh pemberian pesan singkat atau SMS pada pengetahuan, persepsi, dan capaian pelaksanaan IMD yang dilakukan oleh bidan sebagai tenaga penolong persalinan.

\section{METODE}

Jenis penelitian ini adalah kuasi eksperimental dengan rancangan sebelum dan sesudah perlakuan menggunakan kelompok pembanding. Target populasi adalah bidan yang bertempat tinggal dan bekerja di kota Palembang. Populasi diseleksi dengan kriteria inklusi antara lain telah menyelesaikan pendidikan kebidanan, mempunyai izin praktik, memiliki pengalaman membantu persalinan minimal 1 tahun, dan mempunyai alat komunikasi pribadi dan bersedia menerima intervensi yang diberikan. Bidan tidak menjadi responden apabila berdomisili di Palembang namun bekerja di luar kota dan menempati jabatan sebagai pengurus Ikatan Bidan Indonesia (IBI) cabang Palembang. Jumlah bidan yang memenuhi kriteria ditelusuri melalui rekapitulasi IBI dan kantor pusat perizinan terpadu (KPPT) kota Palembang. Target populasi berjumlah 369 orang.

Pengambilan responden penelitian dilakukan dengan teknik cluster sampling. Populasi dibagi menjadi 2 kelompok berdasarkan ranting atau wilayah kerja. Kemudian, satu per satu calon responden diberikan lembar persetujuan melalui pertemuan rutin dan/atau ditemui langsung. Berdasarkan lembar persetujuan, jumlah sampel pada kelompok kontrol sebanyak 54 orang, sedangkan kelompok eksperimen berjumlah 58 orang. Selama masa penelitian berlangsung, sebanyak 48 orang dikeluarkan dari penelitian karena tidak bersedia ditemui dan banyaknya kesibukan lain. Jumlah responden yang mengikuti hingga akhir penelitian berjumlah 64 orang, yang bekerja di rumah sakit (3 orang), klinik atau rumah sakit bersalin 13 orang, puskesmas 24 jam 11 orang, dan praktik swasta 37 orang.

Variabel bebas adalah pemberian perlakuan dengan menggunakan layanan pesan singkat/SMS mengenai IMD. Variabel terikat adalah pengetahuan dan persepsi bidan dan praktik IMD. Sebelum melakukan penelitian, rancangan pesan terlebih dahulu dibuat berdasarkan hasil wawancara dengan 10 bidan yang bekerja di kecamatan Indralaya, kabupaten Ogan Ilir, Sumatera Selatan. Selanjutnya, rancangan template pesan dikonsultasikan pada 
seorang ahli media dan komunikasi sehingga terbentuk 18 tema pesan IMD.

Perlakuan diberikan dengan mengirimkan 18 tema pesan IMD kepada responden kelompok intervensi melalui short message service (SMS) pada ponsel. Setiap 1 tema menjadi 2 template pesan yang dikirimkan pada jam 9 pagi dan 8 malam. Template pesan dikirimkan dengan menggunakan sistem SMS gateway melalui website dengan menggunakan jasa pihak ketiga sebagai penyedia program. Jenis komunikasi yang digunakan merupakan satu arah, penerima pesan hanya dapat menerima pesan tanpa dapat mengirimkan tanggapan atau komentar ke pengirim pesan.

Sebagai bagian dari etika penelitian, perlakuan standar berupa materi pembelajaran tertulis diberikan kepada seluruh responden. Materi pembelajaran ini diadopsi dari "paket modul kegiatan: IMD dan ASI eksklusif 6 Bulan” yang disusun oleh departemen kesehatan tahun 2008 yang berisi tentang pengertian, manfaat, tahapan, dan mitos seputar IMD.

Data primer dikumpulkan dengan menggunakan kuesioner pengetahuan dan persepsi dan lembar checklist pelaksanaan IMD melalui pre test dan post test. Selain itu, data sekunder terdiri dari data jumlah bidan dari IBI dan KPPT dan data persalinan selama masa penelitian pada setiap responden. Kuesioner pengetahuan dan persepsi tidak mengadopsi penelitian sebelumnya. Uji validitas dan reliabilitas pada kuesioner dilakukan saat pre test $(\mathrm{r}>0,3338)$.

Kuesioner disusun untuk mengukur pengetahuan responden mengenai pengertian, manfaat dan langkah IMD (12 pertanyaan), sedangkan kuesioner persepsi terdiri dari pernyataan mengenai persepsi keseriusan konsekuensi akibat tidak melaksanakan IMD, persepsi manfaat pelaksanaan IMD, dan persepsi hambatan pelaksanaan IMD (33 pernyataan). Untuk penilaian terhadap pelaksanaan IMD, lembar check list disusun SOP praktik IMD sejak pemberian informasi saat kehamilan hingga perawatan bayi pasca persalinan (13 tahapan). Penggalian data praktik IMD saat pre test dilakukan kepada responden, sedangkan saat post test digali melalui ibu yang pernah menerima layanan persalinan dari responden. Hal ini bertujuan untuk mendapatkan keabsahan data praktik IMD. Untuk melengkapi data penelitian, catatan lapangan dan dokumentasi dan konfirmasi pada responden melalui tanya jawab.

Data primer diolah melalui tahapan editing, coding, entry dan tabulating. Analisis data menggunakan program STATA seri 12.1. Data yang terkumpul dilakukan uji normalitas melalui uji Saphiro-Wilk test $(a=0,05)$. Analisis bivariabel menggunakan uji t-test, dilanjutkan dengan uji regresi linear.

\section{HASIL}

Sebagian besar responden berumur antara 21-30 tahun dan paling banyak berumur 26 tahun (7 orang). Pada kelompok intervensi, responden termuda berumur 23 tahun (3 orang) dan yang tertua berumur 54 tahun (1 orang), sedangkan pada kelompok kontrol, usia termuda yaitu 22 tahun (1 orang) dan yang tertua 44 tahun (1 orang).

Pendidikan responden pada kedua kelompok didominasi pendidikan D3, sedangkan lama bekerja sebagai bidan dijalani sebagian responden selama lebih dari 5 tahun. Tidak ada perbedaan bermakna pada umur, pendidikan dan lama bekerja antara kedua kelompok. Semua responden menyatakan kebijakan IMD telah ada sejak tahun 2008 atau sejak mereka bekerja di tempat praktik saat ini.

Tabel 1. Perbedaan statistik kelompok perlakuan dan kontrol berdasarkan karakteristik responden

\begin{tabular}{lccc}
\hline \multicolumn{1}{c}{ Karakteristik } & $\begin{array}{c}\text { Perlakuan } \\
(\mathbf{n}=\mathbf{3 3})\end{array}$ & $\begin{array}{c}\text { Kontrol } \\
(\mathbf{n}=\mathbf{3 1})\end{array}$ & P-Value* $^{*}$ \\
\hline Umur (tahun) & Min : 23 & Min $: 22$ & 0,102 \\
& Maks : 54 & Maks : 44 & \\
$21-30$ & 19 & 22 & \\
$31-40$ & 8 & 7 & \\
$41-50$ & 5 & 2 & 0,609 \\
50 tahun ke atas & 1 & - & \\
Pendidikan (\%) & & & \\
D3 & 26 & 5 & \\
D4/S1 & 7 & & \\
Lama bekerja (\%) & & 16 & \\
Kurang dari 2 tahun & 11 & 15 & \\
Lebih dari 2 tahun & 22 & & \\
\hline
\end{tabular}
*Uji T

Hasil pre test dan post test menunjukkan responden mampu menjawab dengan benar sebanyak 6 hingga 11 pertanyaan. Setelah dilakukan uji t-test, perbedaan rerata pengetahuan kelompok intervensi mengalami kenaikan yang signifikan. Perbedaan rerata sebelum dan setelah perlakuan di kelompok intervensi sebesar 1,18 poin. Tidak terdapat perbedaan rerata pengetahuan yang bermakna pada kelompok kontrol, dengan nilai peningkatan sebesar 0,45 poin. Namun, perlakuan tidak terbukti memberikan pengaruh yang signifikan pada pengetahuan responden.

Responden dengan tingkat pengetahuan sangat baik lebih banyak berada pada kelompok intervensi, baik dari hasil pre test dan post test. Peningkatan persentase responden dengan tingkat pengetahuan sangat baik terjadi pada kedua kelompok setelah post test. Tetapi, 
pada kelompok kontrol, jumlah responden dengan tingkat pengetahuan kurang baik sedikit meningkat.

Tabel 2. Pre test dan post test pemberian SMS pesan IMD pada kelompok intevensi dan kontrol

\begin{tabular}{|c|c|c|c|c|}
\hline \multirow[t]{2}{*}{ Variabel } & \multicolumn{2}{|c|}{ Intervensi (n) } & \multicolumn{2}{|c|}{ Kontrol (n) } \\
\hline & Sebelum & Sesudah & Sebelum & Sesudah \\
\hline \multicolumn{5}{|l|}{$\overline{\text { Pengetahuan }}$} \\
\hline Nilai min & 6 & 6 & 5 & \\
\hline Nilai maks & 12 & 12 & 11 & 11 \\
\hline Mean \pm std dev & $8,97 \pm 1,70$ & $10,15 \pm 1,60$ & $8,55 \pm 1,36$ & $9 \pm 1,41$ \\
\hline Diff. & & 1,18 & & 0,45 \\
\hline$p$-value & & $0,0008^{*}$ & & 0,1286 \\
\hline \multicolumn{5}{|c|}{ Tingkatan pengetahuan } \\
\hline Sangat baik ${ }^{\mathrm{a}}$ & 14 & 23 & 8 & 14 \\
\hline Baik $^{b}$ & 11 & 7 & 18 & 11 \\
\hline Kurang baik ${ }^{c}$ & 8 & 3 & 5 & \\
\hline \multicolumn{5}{|l|}{ Persepsi IMD } \\
\hline Nilai min & 54 & 66 & 25 & 64 \\
\hline Nilai maks & 99 & 99 & 94 & 94 \\
\hline Mean \pm std dev & $76,6+11,09$ & $85,4+9,35$ & $73,7+13,1$ & $77,2+7,47$ \\
\hline Diff. & & 8,84 & & 3,46 \\
\hline$p$-value & & $0.0000^{*}$ & & 0.2804 \\
\hline \multicolumn{5}{|c|}{ Tingkatan persepsi } \\
\hline Sangat baik & 7 & $12(36)$ & $1(3)$ & $2(7)$ \\
\hline Baik & 24 & $19(58)$ & $28(90)$ & $20(64)$ \\
\hline Kurang baik & 2 & $2(6)$ & $2(7)$ & $9(29)$ \\
\hline \multicolumn{5}{|c|}{ Pelaksanaan tahapan IMD } \\
\hline Nilai min & 8 & 5 & 5 & 7 \\
\hline Nilai maks & 13 & 11 & 13 & 12 \\
\hline Mean \pm std dev & $10,73+1,64$ & $9,21+1,24$ & $11,1+1,68$ & $9,1+1,22$ \\
\hline Diff. & & $-1,52$ & & -2 \\
\hline$p$-value & & $0.0001^{*}$ & & $0.0000^{*}$ \\
\hline \multicolumn{5}{|c|}{ Tingkatan praktik IMD } \\
\hline Tepat $^{\mathrm{d}}$ & 20 & 3 & 22 & 3 \\
\hline$\underline{\text { Kurang tepat }^{\mathrm{e}}}$ & 13 & 30 & 9 & 28 \\
\hline
\end{tabular}

Sebelum perlakuan diberikan, nilai terendah dimiliki oleh kelompok kontrol sebesar 25 poin, sedangkan pada kelompok intervensi sebesar 54 poin. Berdasarkan uji normalitas, data persepsi sebelum perlakuan dinyatakan berdistribusi tidak normal, sehingga dinormalkan dengan memangkat-2-kan (kuadrat) semua data persepsi.

Rerata persepsi responden setelah perlakuan pada kedua kelompok terlihat meningkat dibandingkan sebelumnya. Namun, peningkatan rerata persepsi yang bermakna hanya terjadi pada kelompok intervensi. Hasil ini diperkuat dengan adanya hubungan antara pemberian perlakuan terhadap peningkatan persepsi responden kelompok intervensi dengan nilai p 0,0308. Setelah dilakukan uji regresi, nilai $\mathrm{R}^{2}$ sebesar 0,0730 , berarti pemberian perlakuan terbukti bermakna meningkatkan persepsi IMD sebesar 7,3 persen dibandingkan dengan kelompok kontrol.

Sebagian besar persepsi responden di kedua kelompok berada pada tingkatan baik saat pre test dan post test. Namun, responden dengan tingkat persepsi sangat baik lebih banyak dimiliki oleh kelompok intervensi dibandingkan kontrol, sedangkan jumlah responden dengan tingkat persepsi kurang baik sama-sama terlihat meningkat pada kedua kelompok.

Sebagian besar butir pernyataan dalam kuesioner persepsi mampu ditanggapi dengan baik oleh responden, walaupun terdapat lima butir pernyataan yang masing ditanggapi keliru (lebih dari 20\% responden). Empat dari lima butir pernyataan yang ditanggapi keliru tergolong dalam persepsi hambatan pelaksanaan IMD. Pernyataan tersebut antara lain mengenai jangka waktu pelaksanaan IMD, pemberian asupan selain ASI untuk bayi baru lahir, hambatan IMD ketika ibu bersalin menolak, IMD pada persalinan caesar, dan respon bayi saat IMD berlangsung.

Efek perlakuan terhadap pelaksanaan IMD. Dari lembar check list, tindakan IMD diakui telah difasilitasi untuk setiap persalinan oleh sekitar $70 \%$ responden pada kelompok intervensi dan kontrol. Hampir 20\% dari responden masih belum melakukan IMD sama sekali. Beberapa responden tidak mendapatkan pasien selama penelitian berlangsung dan responden lain menyatakan kondisi ibu dan bayi saat itu tidak mendukung karena kelelahan dan perdarahan. Rerata pelaksanaan IMD menurun pada hasil post test untuk kedua kelompok. Jumlah tahapan IMD yang terpenuhi oleh kelompok intervensi paling sedikit 8 poin pada pre test menjadi hanya 5 poin, sedangkan kelompok kontrol justru meningkat dari jumlah tahapan minimal 5 poin menjadi 7 poin saat post test. Beberapa responden yang mampu memenuhi seluruh tahapan IMD saat pre test hanya mampu memenuhi 11-12 tahapan saat post test.

Nilai rerata praktik IMD pada kedua kelompok sebelum perlakuan mempunyai perbedaan yang bermakna dibandingkan dengan setelah perlakuan $(p<0,05)$. Akan tetapi, beda rerata tahapan pada kelompok intervensi menunjukkan adanya penurunan, begitu pula dengan kelompok. Pada uji beda selisih nilai rerata pelaksanaan IMD antara kedua kelompok, diketahui tidak ada perbedaan yang bermakna ( $\mathrm{p}=$ 0,2673; 95\% CI= $(-45,6)-(-27,1))$. Dengan demikian dapat dikatakan pemberian intervensi tidak memberikan yang bermakna pada pelaksanaan IMD.

Tidak seluruh tahapan IMD dapat dilakukan oleh responden. Beberapa tahapan IMD hanya dilakukan oleh kurang dari 30\% responden antara lain pemberian informasi IMD saat ANC, bayi dibiarkan mencari sendiri saat IMD, bayi dibiarkan hingga berhasil menemukan ASI, bayi dibiarkan hingga berhasil menghisap ASI, dan pemberian susu formula. Durasi pelaksanaan IMD terjadi rata-rata selama 25-30 menit. 
Sebanyak 47 responden (81\%) menerima semua pesan singkat (delivered) sedangkan 11 responden lain berstatus expired, undelivered, dan rejected. Dari 11 responden tersebut, 3 responden tidak menerima pesan sama sekali (status undelivered dan rejected), 8 responden tidak menerima sebagian pesan.

Tabel 3. Status pengiriman pesan

\begin{tabular}{cl}
\hline \multicolumn{1}{c}{ Status } & \multicolumn{1}{c}{ Keterangan } \\
\hline Delivered & pesan $(S M S)$ terkirim ke nomor HP tujuan \\
Undelivered & pesan tidak terkirim ke nomor HP tujuan, karena \\
& $\bullet$ nomor tujuan tidak aktif/tidak \\
& teridentifikasi/tidak dapat dilacak \\
& $\bullet$ kotak masuk/penyimpanan HP penuh \\
& $\bullet$ HP tidak bisa menerima SMS (khususnya HP \\
& Amerika) \\
Rejected & pesan ditolak oleh SMSC (Short Message Service \\
& Center) dari operator jaringan. Ini terjadi apabila \\
& jaringan tujuan tidak tersedia/diblok oleh \\
& operator jaringan \\
periode pengiriman pesan telah habis. Ini terjadi & apabila nomor HP tujuan tidak aktif dan/ berada \\
& di luar lokasi layanan dalam jangka waktu \\
& tertentu. \\
\hline
\end{tabular}

Secara garis besar, evaluasi ini meliputi tiga hal, tanggapan terhadap kuantitas dan pengiriman pesan, tanggapan kualitas isi pesan dan tanggapan manfaat dari pesan yang diterima. Dari tanggapan pada kuantitas dan pengiriman pesan, diketahui sebanyak 75,76\% (25 orang) responden tidak setuju jika jumlah pesan dikirim memenuhi kontak masuk. Responden menyatakan tidak setuju (96,97\%) jika pesan yang dikirimkan mengganggu aktivitas mereka.

Sebagian besar responden menyatakan bahwa pesan yang dikirimkan mudah untuk dibaca (75,75\%), tidak terlalu panjang dan tidak membosankan (84,85\%), dan pesan tidak sulit dipahami (100\%).

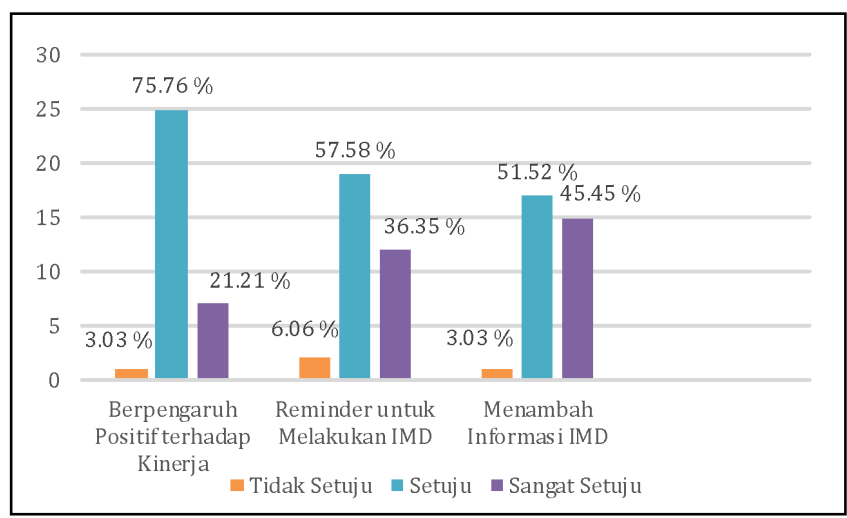

Gambar 1. Tanggapan pada manfaat pemberian pesan

Evaluasi pesan dari sisi manfaat yang diberikan kepada responden dinilai dari tiga butir pernyataan dalam angket, yakni pengaruh terhadap kinerja, manfaat sebagai reminder, dan pengaruh pada penambahan informasi. Pesan yang dikirimkan diakui responden mempunyai pengaruh positif terhadap kinerja, sebagai reminder untuk melaksanakan IMD dan menambah pengetahuan/informasi seputar IMD.

\section{BAHASAN}

Tenaga kesehatan penolong persalinan, terutama bidan, merupakan faktor pendorong pelaksanaan pemberian IMD. Bidan memfasilitasi IMD dengan baik apabila memiliki pengetahuan dan sikap positif (11). Hasil penelitian menunjukkan pengetahuan responden tentang IMD sebelum perlakuan pada kedua kelompok cukup baik dengan nilai rerata di atas 8. Pengaruh pemberian SMS terlihat di peningkatan pengetahuan responden kelompok intervensi, walaupun perubahan rerata dinyatakan tidak bermakna secara signifikan dibandingkan dengan kelompok kontrol.

Penyebab intervensi kurang berpengaruh secara signifikan adalah faktor tingkat pendidikan dan pengalaman responden. Seluruh responden telah menempuh pendidikan minimal D3 kebidanan. Menurut Maryam, semakin tinggi tingkat pendidikan seseorang, maka kemampuan penerimaan informasi semakin baik (12). Selain itu, ketika mengurus izin praktik, bidan diharuskan menerima pelatihan asuhan persalinan normal (APN) yang salah satu materi yang diberikan adalah tentang penatalaksanaan IMD.

Pemberian SMS memberikan perubahan signifikan terhadap pengetahuan remaja laki-laki dan perempuan di Australia mengenai penyakit menular seksual dan penggunaan kondom (9). Namun, temuan berbeda dikemukakan dalam penelitian Lau et al., pemberian SMS tidak menunjukkan perbedaan signifikan pada ibu hamil mengenai ANC. Pesan singkat sudah sampai pada penerima tetapi responden mungkin tidak membaca pesan tersebut (13).

Persepsi juga mampu membentuk perilaku IMD. Persepsi responden pada awal penelitian cukup positif dan cenderung meningkat setelah perlakuan diberikan, terutama pada kelompok intervensi yang mengalami perubahan signifikan. SMS cukup efektif dalam memotivasi perubahan perilaku pada penderita hipertensi. Pemberian SMS sebagai reminder menjadi sumber informasi yang mengingatkan responden saat melakukan kegiatan sehari-hari (14).

Jumlah pelaksanaan IMD cenderung menurun setelah perlakuan pada kedua kelompok. Secara kualitas, pemberian perlakuan juga dinyatakan tidak bermakna terhadap peningkatan tahapan pelaksanaan IMD. Hal ini disebabkan karena banyak responden yang drop out, penggalian informasi yang dilakukan 
pada sumber berbeda (bidan (pre test) dan ibu bersalin (post test)), dan waktu penelitian yang singkat. Periode perlakuan singkat pada penelitian lain menyebabkan kesulitan menentukan perubahan atau dampak jangka panjang, termasuk perilaku responden (15).

Penelitian ini menemukan beberapa hambatan dan kekeliruan pada pemahaman responden. Kekeliruan mencakup tentang hambatan ketika ibu menolak IMD dan hanya diberikan pada persalinan normal, jangka waktu pelaksanaan IMD dianggap lama, pemahaman yang kurang mengenai respon bayi saat IMD, dan ada pemberian asupan pada bayi selain ASI.

Tindakan IMD hanya diberikan pada ibu dan bayi yang menjalani proses persalinan normal dan dinilai tidak mengkhawatirkan pasca persalinan. Selain itu, sebagian besar IMD tidak dilakukan jika ibu menolak dengan pertimbangan keadaan ibu yang masih lemah dan terlihat lelah. Penelitian lain menemukan masih ada penolong persalinan yang belum yakin manfaat IMD, sehingga cenderung tidak melakukan IMD bila terjadi hambatan (11).

Rerata lama pelaksanaan IMD adalah 25 hingga 30 menit, dan paling singkat selama 5 menit. Responden menganggap IMD terlalu lama jika dilakukan selama 1 jam dan tidak ada cukup petugas untuk menjaga bayi selama IMD berlangsung. Kegagalan IMD salah satunya disebabkan karena waktu pelaksanaan yang lama (16), dan biasanya bidan memiliki keterbatasan waktu (11). Padahal, proses menyusu dini sebaiknya dilakukan maksimal 1 hingga 2 jam setelah persalinan karena dapat mempertahankan kemungkinan ibu menyusui bayinya hingga 4 bulan (17).

Pemahaman bidan yang kurang mengenai perilaku bayi saat menyusu pertama kali menyebabkan bidan sering kali mengarahkan mulut bayi dekat dengan puting susu ibu, bahkan memasukkannya ke mulut bayi. Sebagian besar bidan menganggap IMD adalah membantu menyusukan bayi setelah ibu bersalin (18). Sementara, Mashudi menyatakan bahwa unsur 'menyusu' pada istilah IMD berarti bayi seharusnya secara aktif menemukan sendiri puting susu ibu, bukan dibantu bidan atau ibu sendiri. Tindakan memisahkan bayi sebelum berhasil menemukan puting susu menyebabkan hormon prolaktin dalam darah ibu menurun dan sulit distabilkan sehingga produksi ASI menjadi kurang lancar (11).

Pemberian makanan prelaktal tidak diberikan oleh responden secara langsung, tapi anggota keluarga ibu bersalin sebagai bagian dari adat/budaya. Tetapi, bidan masih menganggap bahwa pemberian madu kepada bayi saat ASI belum keluar masih termasuk dalam kategori ASI eksklusif (18).
Intervensi menerima beberapa tanggapan positif dan negatif dari responden. Frekuensi pesan singkat sebanyak 2 kali sehari dengan topik yang sama dinilai repetitif, sehingga sebaiknya hanya 1 pesan per hari atau 3 pesan per minggu (19). Tanggapan positif juga disampaikan oleh beberapa responden yang menyatakan ketertarikan untuk mengadopsi metode serupa untuk menunjang kegiatan di lingkungan kerjanya. Intervensi ini juga tergolong efisien dengan biaya yang cukup terjangkau dan mudah diterapkan untuk program intervensi lain.

Intervensi pada perilaku IMD bidan memperhatikan beberapa hal dan tidak dan merta mampu diubah dalam waktu singkat. Beberapa studi telah memperlihatkan dampak positif dari penggunaan pesan singkat, namun tidak berarti semua program efektif mengubah pengetahuan, sikap, persepsi, bahkan perilaku seseorang. Waktu, frekuensi dan durasi pelaksanaan dan pembentukan pesan perlu digali lebih jauh sebagai bagian dari kunci kesuksesan sebuah program kesehatan. Hal terpenting adalah pesan singkat merupakan salah satu model dalam penyampaian informasi/pesan (20).

\section{SIMPULAN}

Pemberian intervensi berupa pesan singkat berpengaruh pada persepsi bidan tentang IMD. Tingkat penerimaan responden terhadap model penyampaian informasi melalui pesan singkat dianggap baik. Penelitian ini dapat digunakan sebagai studi pendahuluan guna mengidentifikasi permasalahan yang dihadapi bidan dalam pelaksanaan IMD sehingga penyusunan materi/isi pesan dapat disesuaikan dengan kebutuhan lapangan.

\footnotetext{
Abstrak

Tujuan: Penelitian ini bertujuan melihat pengaruh pemberian pesan singkat terhadap perilaku IMD pada bidan. Metode: Jenis penelitian ini adalah quasi-experimental melalui before and after design dengan kelompok kontrol. responden penelitian berjumlah 64 bidan di Kota Palembang. Perlakuan yang diberikan berupa 18 topik pesan edukasi tentang IMD dalam bentuk pesan singkat melalui handphone. Data dianalisis melalui uji univariat, bivariat, dan regresi linear. Hasil: Pemberian perlakuan meningkatkan persepsi tentang IMD sebesar 7,3\% ( $p$-value $=0,0308)$. Pengetahuan kelompok intervensi meningkat setelah perlakuan,
} 
walaupun perubahan rerata tidak bermakna dibandingkan dengan kelompok kontrol. Sebagian besar responden kurang tepat menjalankan tahapan IMD, antara lain tentang pemberian informasi IMD saat ANC, durasi IMD yang singkat, dan bayi masih diarahkan saat IMD. Simpulan: Pelaksanaan IMD belum dijalankan secara maksimal oleh bidan. Tidak semua persalinan difasilitasi IMD karena keadaan ibu dan bayi tidak mendukung. Bidan sebaiknya dapat memberikan motivasi ibu bersalin, dimulai saat pemeriksaan kehamilan. Komitmen dan kepercayaan diri merupakan kunci dari keyakinan bidan untuk senantiasa memfasilitasi IMD pada setiap persalinan. Selain itu, hasil penelitian ini perlu dianalisis jangka panjang untuk dampak yang lebih signifikan.

Kata kunci: inisiasi menyusu dini; intervensi; pesan singkat; perilaku; bidan

\section{PUSTAKA}

1. Keisling K. mHealth Field Guide for Newborn Health. Washington DC: CORE Group; 2014.

2. Vital Wave Consulting. mHealth for Development : The Opportunity of Mobile Technology for Healthcare in the Developing World. Washington DC and Berkshire: UN Foundation-Vodafone Foundation Partnership; 2009.

3. Rahmaningtyas I, Wijanti RE, Hardjito $\mathrm{K}$. Perbedaan Kekuatan Kontraksi Uterus Pada Ibu Post Partum Antara Sebelum dan Sesudah Melaksanakan Inisiasi Menyusu Dini (IMD). J Penelit Kesehat Suara Forikes. 2010;1(3):205-9.

4. Dinas Kesehatan Kota Palembang. Profil Seksi Pelayanan Kesehatan Dasar (PKD) Tahun 2013. Palembang; 2013.

5. Nabulsi M, Hamadeh $\mathrm{H}$, Tamim $\mathrm{H}$, Kabakian T, Charafeddine L, Yehya N. A complex breastfeeding promotion and support intervention in a developing country: study protocol for a randomized clinical trial. BMC Public Health [Internet]. 2014;14(36):1-11.

6. Digirolamo AM, Grummer-strawn LM, Fein SB. Effect of Maternity-Care Practices on Breastfeeding. Pediatrics [Internet]. 2008;122(October):43-9. Available from: www.pediatrics.org

7. Afifah. Inisiasi Menyusu Dini dan Pemberian Air Susu Ibu Eksklusif di Kecamatan Johan Pahlawan Kabupaten Aceh Barat. Universitas Sumatera Utara; 2009.

8. Setiarini T. Faktor-Faktor Yang Berhubungan Dengan Kinerja Bidan dalam Pelaksanaan Inisiasi Menyusu Dini di RSIA Budi Kemuliaan Jakarta. Universitas Indonesia; 2012.

9. US Department of Health and Human Services. Using Health Text Messages to Improve Consumer Health Knowledge , Behaviors, and Outcomes : An Environmental Scan. Maryland: US Department of Health and Human Services; 2014.
10. Soegijoko S. Telemedika dan E-Health serta Prospek Aplikasinya di Indonesia. In: Seminar Nasional Aplikasi Teknologi Informasi. Yogyakarta: Teknik Informatika Fakultas Teknologi Industri Universitas Islam Indonesia; 2010.

11. Aryani F. Gambaran Perilaku Bidan Dalam Pelaksanaan Inisiasi Menyusu Dini (IMD) di Puskesmas Kecamatan Pesanggrahan Jakarta Selatan. Universitas Islam Negeri Syarif Hidayatullah; 2013.

12. Ariwati VD, Rosyidi MI, Pranowowati P. Hubungan Dukungan Bidan Tentang Pemberian ASI Eksklusif Dengan Perilaku Pemberian ASI Eksklusif di Wilayah Kerja Puskesmas Ambarawa Kabupaten semarang. Kabupaten Semarang: STIKES Ngudi Waluyo Ungaran; 2014. p. 1-15.

13. Lau YK, Cassidy $T$, Hacking $D$, Brittain $K$, Haricharan HJ, Heap M. Antenatal health promotion via short message service at a Midwife Obstetrics Unit in South Africa : a mixed methods study. BMC Pregnancy Childbirth. 2014;14(284):1-8.

14. Hacking D, HJ H, K B, YK L, T C, M H. Hypertension Health Promotion via Text Messaging at a Community Health Center in South Africa: A Mixed Methods Study. JMIR mHealth uHealth [Internet]. 2016;4(1).

15. Holtz B, Lauckner C, Ann VA, Arbor A, Studies I, Lansing E. Diabetes Management via Mobile Phones: A Systematic Review. Telemed e-Health. 2012;18(3):175-85.

16. Rita L. Pengaruh Peran Dukungan Suami Terhadap Lama Waktu Keberhasilan Inisiasi Menyusu Dini. BHAMADA. 2014;5(1):71-7.

17. Nakao Y, Moji K, Honda S, Oishi K. Initiation of breastfeeding within 120 minutes after birth is associated with breastfeeding at four months among Japanese women: A self-administered questionnaire survey. Int Breastfeed $\mathrm{J}$. 2008;7(Table 1):1-7.

18. Aprillia Y. Analisis Sosialisasi Program Inisiasi Menyusu Dini dan ASI Eksklusif Kepada Bidan di Kabupaten Klaten. Universitas Diponegoro; 2009.

19. Abroms LC, Whittaker R, Free C, Mendel J, Alstyne V, Schindler-ruwisch JM. Developing and Pretesting a Text Messaging Program for Health Behavior Change: Recommended Steps Corresponding Author: JMIR Mhealth Uhealth [Internet]. 2015;3(4).

20. Lim MSC, Wright C, Hons B, Hellard ME. The Medium and the Message : Fitting Sound Health Promotion Methodology Into 160 Characters. JMIR Mhealth Uhealth. 2014;2(4). 
